\title{
Sugammadex reversal of large subcutaneous injection of rocuronium in an obese patient
}

\author{
Dae-Hoon Kim, Sung Min Kim, Joungmin Kim, Seongtae Jeong \\ Department of Anesthesiology and Pain Medicine, Chonnam National University Medical School and Hospital, Gwangju, Korea
}

\author{
Received September 5, 2019 \\ Revised September 20, 2019 \\ Accepted September 23, 2019 \\ Corresponding author \\ Seongtae Jeong \\ Department of Anesthesiology and \\ Pain Medicine, Chonnam National \\ University Medical School and \\ Hospital, 42, Jebong-ro, Dong-gu, \\ Gwangju 61469, Korea \\ Tel: +82-62-220-6893 \\ Fax: +82-62-232-6294 \\ E-mail: anesjst@jnu.ac.kr \\ ORCID: \\ http://orcid.org/0000-0002-6245-9779
}

\begin{abstract}
In obese patients, correct insertion of the intravenous line and early identification of subcutaneous injection may be difficult. We report management of accidental subcutaneous rocuronium administration in a 38-year-old, obese Korean woman undergoing elective breast cancer surgery. The perioperative management of the patient is discussed, and a review of the literature is provided. Little information is available regarding the absorption of medications outside of the typical route of administration. The accidental subcutaneous infiltration of neuromuscular blocking agents may lead to pulmonary complications. Early identification of subcutaneous infiltration is important and open discussion with many treatment team members is critical. Careful monitoring including neuromuscular monitoring in the post-anesthesia care unit is essential.
\end{abstract}

Keywords: Rocuronium; Subcutaneous injection; Sugammadex

\section{INTRODUCTION}

Little is known about the effects of neuromuscular blocking agents outside of intravenous administration. Although most episodes of medication extravasation do not cause significant sequelae, serious injury, such as tissue necrosis, scarring around tendons, and prolonged unwanted medication effects, may occur [1]. Significant adverse events may occur due to the accidental infiltration of neuromuscular blocking agents, which may compromise the patient's pulmonary function [2,3]. Open communication with the surgical team and attentive monitoring and management are necessary to prevent adverse events of patients with extravasation of neuromuscular blocking agents.

\section{CASE REPORT}

A 38-year-old Korean woman was scheduled for left modified radical mastectomy because of breast cancer. She had no history of underlying disease, such as hypertension, dyslipidemia, or diabetes mellitus. She entered the operating room with two intravenous lines: one in the right cephalic vein with a 20G catheter and the other in the great saphenous vein of the left leg with a $24 \mathrm{G}$ catheter. Multiple attempts were made to insert the intravenous line but the patient's obesity (BMI, 32.88; total body weight, $82 \mathrm{~kg}$ ) made intravenous catheterization difficult in the ward.

Before drug injection, the functions of the two intravenous lines were checked and no swelling was noted at the intra-

This is an Open Access article distributed under the terms of the Creative Commons Attribution Non-Commercial License (http://creativecommons.org/licenses/by-nc/4.0) which permits unrestricted noncommercial use, distribution, and reproduction in any medium, provided the original work is properly cited. Copyright $(\subset)$ Medical Biological Science and Engineering. 
venous catheterization sites. The patient did not complain of pain on fluid loading via the intravenous line. Induction of anesthesia was performed with $150 \mathrm{mg}$ propofol via the right cephalic intravenous line and remifentanil at $50 \mu \mathrm{g}$ via the left great saphenous intravenous line. After confirming sedation of the patient by bispectral index monitoring, we injected rocuronium at $50 \mathrm{mg}(0.6 \mathrm{mg} / \mathrm{kg})$ via the left great saphenous intravenous line as blood pressure was checked on the right arm. After allowing for an appropriate time for onset of action, the patient was sedated but still breathing spontaneously with train-of-four (TOF) monitoring on the right ulnar nerve maintaining a ratio of $>90 \%$. Swelling and a change in skin color were detected at site of left great saphenous vein catheterization. The left great saphenous intravenous line was immediately removed and blood was squeezed out.

Rocuronium at $50 \mathrm{mg}(0.6 \mathrm{mg} / \mathrm{kg})$ and remifentanil at $25 \mu \mathrm{g}(0.3 \mu \mathrm{g} / \mathrm{kg})$ were injected for endotracheal intubation via the right cephalic intravenous line. One attempt at direct laryngoscopy was made, and successful intubation was obtained. A new intravenous line was placed in the great saphenous vein on the patient's right ankle with a $22 \mathrm{G}$ catheter while anesthesia was maintained with 6 vol\% of desflurane and remifentanil infusion. The surgical team was notified immediately of the incident, and the procedure commenced. To facilitate absorption of infiltrated rocuronium, we covered the patient's lower limbs with a warm blanket.

The patient's TOF response was monitored closely throughout the procedure. The patient did not show the return of all four twitches at around $160 \mathrm{~min}$. At the end of the procedure, after a period of approximately $180 \mathrm{~min}$, all four twitches then returned. The patient opened her eyes and attempted extubation with the left hand $4 \mathrm{~min}$ after administration of sugammadex sodium at $160 \mathrm{mg}(2 \mathrm{mg} / \mathrm{kg})$. As the patient was compliant, breathing spontaneously, and maintained a tidal volume of $340 \mathrm{~mL}(4 \mathrm{~mL} / \mathrm{kg})$ with a respiratory rate of $12 / \mathrm{min}$, she was extubated and observed for about $10 \mathrm{~min}$ in the operating room. After confirming that the patient was breathing well and TOF ratio $>90 \%$, she was taken to the postanesthesia care unit (PACU).

As we were concerned about the possibility of recurarization of rocuronium, we continued to monitor TOF, end tidal carbon dioxide, and respiratory rate in PACU for $4 \mathrm{~h}$ (Fig. 1). The patient's TOF ratio was maintained at more than $90 \%$, and respiratory rate was maintained at $>12 /$ min until PACU discharge. Approximately $220 \mathrm{~min}$ later, the patient was transferred to the ward without any adverse events.

\section{DISCUSSION}

Residual muscle paralysis can lead to the increase in perioperative morbidity and mortality [2]. Residual neuromuscular blockade due to prolonged effect of rocuroium associated with post operative hypoxemia, airway obstruction and emergent reintubation [3]. The effect of rocuronium is longer in obese patients compared to normal weight patients when given the same dose [4]. In general, the absorption of a subcutaneously injected drug is determined by transport in the extracellular matrix of the subcutaneous tissue, absorption into the blood or lymphatics, and drug properties such as molecular weight and charge [5].

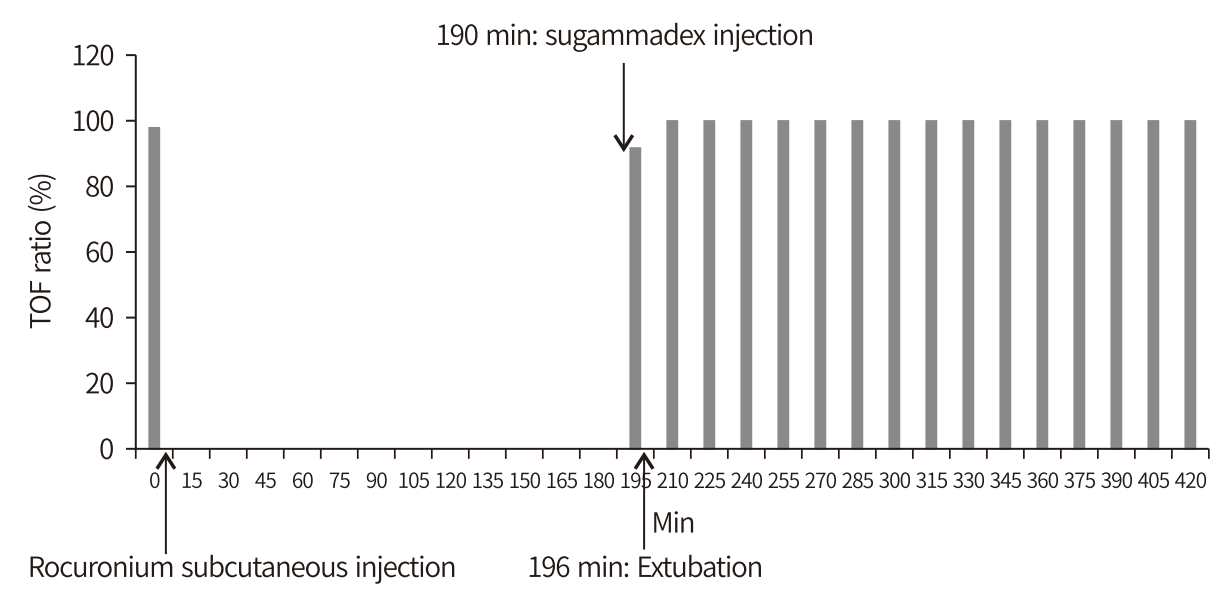

Fig. 1. TOF (Train-of-four) ratio after subcutaneous injection of rocuronium. 
It is reported that subcutaneous injection of neuromuscular blocking agent led to a significant increase in onset time and recovery time compared to intravenous injection [6,7]. In addition, recovery time of a subcutaneous injection of neuromuscular blocking agent to the lower extremity was longer than an injection to the upper extremity [7]. It is related to the differences of the blood flow at various sites of the body [8].

Recently, two cases of accidental subcutaneous rocuronium administration have been reported. Awad et al. [9] described a 65-year-old woman who received subcutaneous injection of $50 \mathrm{mg}$ rocuronium $(0.44 \mathrm{mg} / \mathrm{kg})$. Propofol (100 mg) and vecuronium (5 mg) were injected via a new intravenous line. The patient showed the return of all four twitches at around $60 \mathrm{~min}$. At the conclusion of the procedure, approximately $107 \mathrm{~min}$ later, the patient was taken to the PACU while still intubated because it was necessary for the patient to lie flat for $4 \mathrm{~h}$. After $4 \mathrm{~h}$, the patient was fully reversed with $5 \mathrm{mg}$ neostigmine and $0.8 \mathrm{mg}$ glycopyrrolate without issue. In another case, Navare et al. [10] reported a 69-year-old man with a history of hemodialysis due to end-stage renal disease. In this case, $100 \mathrm{mg}$ rocuronium $(1.16 \mathrm{mg} / \mathrm{kg})$ was injected subcutaneously. After discovery of the accidental infiltration of rocuronium, succinylcholine was injected via a new intravenous line. The TOF response was 1 until the end of the $75 \mathrm{~min}$ procedure. The patient received $4 \mathrm{mg} / \mathrm{kg}$ sugammadex. With $90 \mathrm{~s}$ of sugammadex administration, the TOF response showed four vigorous and equal muscle contractions. The patient also met the clinical criteria for extubation, and was therefore extubated in the operating room. The patient was monitored in the PACU for $5 \mathrm{~h}$ without issue.

A large dose rocuronium prolonged the duration of action as the time to return of the first TOF response. The mean duration of the normal dose rocuronium $(0.83 \mathrm{mg} / \mathrm{kg})$ was $32 \mathrm{~min}$, the $95^{\text {th }}$ percentile is restored for 58 minutes. In comparison, large dose of rocuronium $(1.04 \mathrm{mg} / \mathrm{kg}) \mathrm{had}$ a mean recovery time of 46 minutes, and the $95^{\text {th }}$ percentile recovery time is 70 minutes [11]. However, no data are available regarding the elimination half-life or prolongation of the clinical effects of rocuronium when administered subcutaneously.

The two options for reversal of rocuronium are neostigmine/glycopyrrolate or sugammadex. The novel mechanism of action of sugammadex suggests a solution to these concerns with the potential for neuromuscular blockade reversal even in the absence of a visible twitch response and continuous neutralization of any further absorbed rocuronium. Compared to neostigmine, sugammadex shows significant improvement in residual muscle paralysis [3,12].

In our case, the patient was young and had no underlying disease, and TOF counts was 4 at the end of the operation. Therefore, the possibility of recurarization was lower than in the previous case $[9,10]$, we chose to follow the recommendations in the package insert to reverse "moderate block" (sugammadex $2 \mathrm{mg} / \mathrm{kg}$ ). We monitored the patient for $4 \mathrm{~h}$ after extubation in the PACU. There were two reasons for this. First, sugammadex has a $t_{1 / 2}$ of about $2 \mathrm{~h}$ in adults with normal renal function. Recurarization may have been possible if the absorption of rocuronium occurred $2 \mathrm{~h}$ after sugammadex injection. Second, Awad et al. [9] monitored their obese patient for $4 \mathrm{~h}$ in the recovery room with intubation until $4 \mathrm{~h}$, and Navare et al. [10] monitored their patient in the PACU for $5 \mathrm{~h}$. We concluded that the patient should be monitored for at least $4 \mathrm{~h}$.

This case was caused mainly by the fact that the patient's intravenous line was inserted incorrectly. The obesity in our patient made initial identification of the accidental infiltration of the intravenous line difficult. The risk of extravasation is higher in patients of advanced age, neonates, infants, children, and in those with a history of multiple intravenous therapy, obesity, peripheral neuropathy, and diabetes. Other authors have also reported difficulty with peripheral venous access in obese patients [13].

To prevent extravasation, before injection of drugs, medical staff must check "flashback" of blood returning from the cannula on insertion and resistance to injection, speed of drips, and swelling of the cannula insertion site. In our case, the patient did not feel pain when flushed with saline and there was no swelling of the cannula insertion site. The drip speed was thought to be appropriate for a $24 \mathrm{G}$ catheter. However, we did not check the blood returning from cannula. Therefore, we did not detect the possibility of the extravasation. Careful check before injection of drugs will prevent the extravasation especially in obese patient.

Based on our observations of this case, before injection of the drug, the patient's intravenous line should be carefully checked. We suggest sugammadex as the drug of choice in 
cases with accidental subcutaneous rocuronium injection. We recommend careful patient monitoring including TOF monitoring. Little information is available regarding accidental subcutaneous infiltration of neuromuscular blocking agents. Further studies of the effects of neuromuscular blocking agents are needed to achieve good clinical outcomes.

\section{CONFLICT OF INTEREST}

No potential conflict of interest relevant to this article was reported.

\section{REFERENCES}

1. Lake C, Beecroft CL. Extravasation injuries and accidental intra-arterial injection. Contin Educ Anaesth Crit Care Pain 2010;10:109-13.

2. Murphy GS, Szokol JW, Avram MJ, Greenberg SB, Shear TD, Vender JS, et al. Residual neuromuscular block in the elderly: incidence and clinical implications. Anesthesiology 2015;123:1322-36.

3. Murphy GS, Szokol JW, Marymont JH, Greenberg SB, Avram MJ, Vender JS. Residual neuromuscular blockade and critical respiratory events in the postanesthesia care unit. Anesth Analg 2008;107:130-7.

4. Leykin Y, Pellis T, Lucca M, Lomangino G, Marzano B, Gullo A. The pharmacodynamic effects of rocuronium when dosed according to real body weight or ideal body weight in mor- bidly obese patients. Anesth Analg 2004;99:1086-9.

5. Richter WF, Bhansali SG, Morris ME. Mechanistic determinants of biotherapeutics absorption following SC administration. AAPS J 2012;14:559-70.

6. Tarmey NT, Edward AM, Eynon CA. Prolonged neuromuscular block following accidental subcutaneous injection of vecuronium. Anaesthesia 2011;66:956-7.

7. Iwasaki H, Namiki A, Omote T, Omote K. Neuromuscular effects of subcutaneous administration of pancuronium. Anesthesiology 1992;76:1049-51.

8. Tsuchida Y. Regional differences in the skin blood flow at various sites of the body studied by xenon 133. Plast Reconstr Surg 1987;80:705-10.

9. Awad N, Zalut S, Deutsch E. Successful management of subcutaneous infiltration of an intubating dose of rocuronium in a morbidly obese patient: a case report. J Anaesth Crit Care Case Rep 2018;4:21-3.

10. Navare SR, Garcia Medina O, Prielipp RC, Weinkauf JL. Sugammadex reversal of a large subcutaneous depot of rocuronium in a dialysis patient: a case report. A A Pract 2019;12:375-7.

11. Kirkegaard-Nielsen H, Caldwell JE, Berry PD. Rapid tracheal intubation with rocuronium: a probability approach to determining dose. Anesthesiology 1999;91:131-6.

12. Abad-Gurumeta A, Ripollés-Melchor J, Casans-Francés R, Espinosa A, Martínez-Hurtado E, Fernández-Pérez C, et al. A systematic review of sugammadex vs neostigmine for reversal of neuromuscular blockade. Anaesthesia 2015;70:1441-52.

13. Prakash S, Arora G, Rani HS. Peripheral venous access in the obese patient. Indian J Anaesth 2015;59:692-3. 